\title{
Dance like Bacteria Wonder with Me! Embracing Microbiology through Science and Art from Primary School to University
}

\author{
John D. I. Harper ${ }^{\mathrm{a}}$, Celia R. Connor ${ }^{\mathrm{a}}$, Dominique Sweeney ${ }^{\mathrm{b}}$, Zoë Hadler ${ }^{\mathrm{b}}$, Tricia Warrington ${ }^{\mathrm{c}}$, \\ Thiru Vanniasinkam ${ }^{\mathrm{d}}$ \\ Corresponding author: John Harper (jharper@csu.edu.au) \\ ${ }^{\text {a }}$ School of Agricultural \& Wine Sciences, Charles Sturt University, Wagga Wagga, NSW 2678, Australia \\ ${ }^{\mathrm{b}}$ School of Communication \& Creative Industries, Charles Sturt University, Wagga Wagga, NSW 2678, Australia \\ ${ }^{\mathrm{c}}$ The Bidgee School, Wagga Wagga, NSW 2650, Australia \\ ${ }^{\mathrm{d}}$ School of Biomedical Sciences, Charles Sturt University, Wagga Wagga, NSW 2678, Australia
}

Keywords: acting, arts, outreach, science, transdisiplinarity

\begin{abstract}
The literature tells us that art can enhance the teaching of science. We have used some of these documented strategies in our teaching of microbiology in primary - and high school outreach and in our microbiology classes at university. We have blended art and science in a variety of ways (e.g. dancing and telling stories) to provide our students with richer, more memorable learning experiences. Primary school students were treated to a day of immersion in microbiology where songs, animations, peer learning, art and baking became integral to their learning. For high school outreach, we imagined time travel and invited university acting students to play scientists telling their stories from history to bring to life 'moments' in microbiology. At university, first-year students danced like bacteria to reinforce the types of movement and appendages that some bacteria have. Humour, poetry, songs and mnemonics were also used to not only enhance learning but to remind students that learning is fun and encompasses all aspects of life. We continue to explore a transdiciplinarity approach were the boundaries between disciplines are blurred and the artist becomes a scientist and vice versa on a creative holistic learning journey of discovery.
\end{abstract}

\section{Introduction}

Big fleas have little fleas upon their backs to bite 'em, And little fleas have lesser fleas, and so, ad infinitum...

Augustus De Morgan (1915)

This poem - recited by a high school teacher in my fourteenth year $(\mathrm{JH})$ - left a lasting impression on me. It was my first experience with the use of rhyme as an aid to learning in science. The use of rhyme meant the phrases had a flow that naturally lent themselves to being remembered. I have never forgotten this and to this day I use mnemonics to help my students remember facts, names and terminology in my science teaching. This rhyme has even greater resonance for me now that I teach microbiology at university and in school outreach activities and is one of the artistic strategies I use to engage my students.

There are many historical examples of imagination and creativity enhancing the process of science. In a review of Nobel laureates and other award-winning scientists, it was noted that increased success in the field of science was often accompanied by an increased ability in the creative arts (Scheffer et al., 2015). Indeed our most famous scientist, Albert Einstein, attributed his love of music as enabling him to solve the mathematical complexities of his science discoveries (Viney, 2016). In another study sampling 40 scientists from the late $20^{\text {th }}$ Century, it was found that scientists with a fine art or craft hobby were more likely to be 
successful scientists than their non-artisan colleagues (Root-Berstein, Bernstein, \& Garner, 1995).

Contemporary examples of the Art-Science synergy are also plentiful. Ex-NASA physicist, Robert J Lang (2019) is one of the foremost experts in using origami to solve real-world practical problems. His work includes creating model solar panels out of folded paper that were later deployed in space. He has also had his origami art works commissioned by museums. In addition, there are many publications, including some from economic journals, that provide evidence that engagement with the arts leads to citizens who are more creative and entrepreneurial (LaMore et al., 2013). In Australia, during the International year of Astronomy in 2009 a collaboration was initiated between astrophysicists building the Square Kilometre Array, the largest telescope on Earth, and Indigenous artists living in the region. This process was a joint project to enhance the reconciliation process and yet both the artists and the astrophysicists report inspiration as a result of the collaboration (Tingay, 2018).

Our society is increasingly dependent on scientific literacy across the whole spectrum of career choices. However, in many parts of the world there is a general decline in science literacy that can be in some part attributed to a focus on reading and mathematics (Halpine, 2004). In Australia, the science curriculum at the entry point primary school level is approximately 2 hours per week (Primary School Science Teaching Survey 2014) and the secondary school time 4 hours (OECD, 2014). With such a paucity in science teaching time, it makes sense to utilise the time effectively and incorporate a range of techniques to engage and excite young people about learning. Employing a range of visual and hands on craft or art practices can motivate independent learning and acts to integrate scientific understanding with the young person's view of the world (Papert, 1980). Such practices used to support science literacy have important educational implications in light of the marginalisation of science in many school curricula (Scheffer et al., 2015).

As educators, we asked ourselves what techniques we could employ to engage our students further in science to expand and deepen their understanding of scientific concepts. We provide examples of art-based strategies we have used from primary to tertiary level, that are supported by evidence in the literature, to increase engagement of students with science. Our intention was not to rigorously evaluate these approaches but to use activities that have been evaluated in the literature and incorporate them as part of a suite of activities to enhance the student learning experience. As such this paper provides a starting point providing examples of our exploration of creativity in the teaching of Microbiology and the synergies that happen when scientists embrace their art and artists and scientists work together.

\section{First year microbiology}

In a first year university microbiology class, we service teach over 500 students. Microbiology supports 16 degrees which range from agriculture to medical science. Approximately 75-80\% of these students are first in their family to attend university and 17\% are low SES (Ranshaw $\&$ Wise, 2014). About $60 \%$ of our students are studying online (Distance Education) and come to a four-day intensive residential school to study and be examined on the practical component of the subject. In 2008 there were two first year microbiology subjects in the university. One catered for agriculture and wine students and the other was taught to biomedical students. These courses were merged to create the current one (MCR101) which in its first year of teaching in 2009 had both high attrition and failure rates above the previously taught courses. Faced with these challenges the microbiology teaching team got together and researched the teaching literature to find strategies that would support such a wide cohort of students and 
increase pass rates and satisfaction, while reducing attrition, without compromising quality. Over the next three years a number of different concurrent strategies were employed to improve the subject. This saw an increase in satisfaction in the subject with Likert scores for overall satisfaction going from 4.6 in 2009 to 5.8 in 2012 with 7 being the highest satisfaction rating. Over the same period, the combined on line and on campus attrition rates dropped from $18 \%$ to $5 \%$. As part of our improved teaching strategies I $(\mathrm{JH})$ incorporated, dance, stories, song, humour, poetry and mnemonics into the course. We did not specifically set out to evaluate these individual initiatives for their efficacy in improving our student's learning experience, because they were part of a multiple improvement approach based on published evidence and the hoped for outcomes were achieved. Since then the arts component in teaching microbiology has grown and is set to develop more, as transdisciplinary approaches are sought and we embark on a creative journey with our artist colleagues. Below are some examples of these approaches.

\section{Dancing like bacteria}

Motility is an important attribute of certain bacteria and underpins, for example, their dispersive ability, colonisation and infectivity (Moens \& Vanderleyden, 1996; Haiko \& Westerlund-Wikström, 2013). Those bacteria that can swim have hair-like motile attachments called flagella. The bacteria move with a characteristic 'run and tumble' motion with the run being movement, for example, toward a food source and the tumble being a check of where they are in relation to the stimulus. Different species of swimming bacteria have differences in the placement and number of flagella; for instance, the well-known gut bacteria, Escherichia coli, is peritrichous having flagella around its cell body (peri-around, trichous - hairs). We teach the students about other types of flagellar arrangement: Monotrichous: a single flagellum at one end of the cell; Lophotrichous - a tuft of flagella at one end; amphitrichous - a flagellum at each end; atrichous -without flagella.

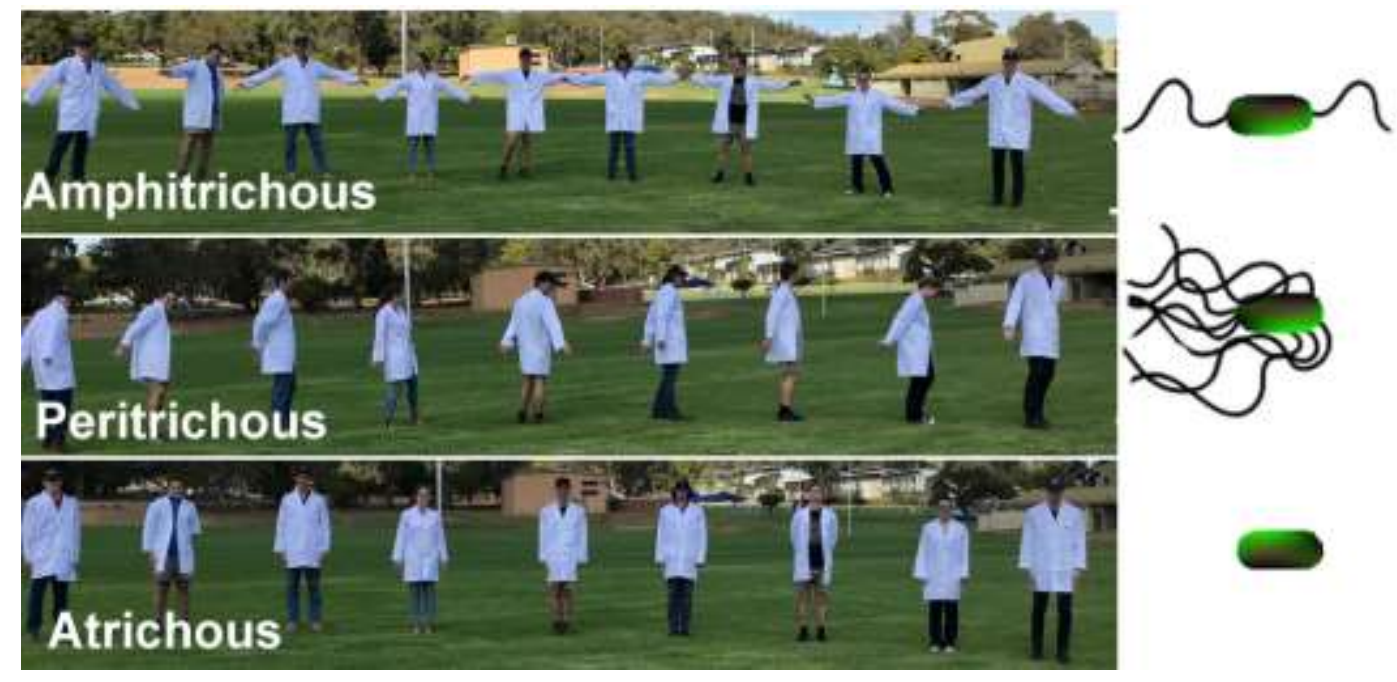

\section{Figure 1: Students demonstrate how to dance like bacteria! Bacterial diagrams showing flagellar arrangement on the right.}

There is evidence in the literature that dancing is used successfully to help students learn. As for learning Science, an interview by Holly Welham (2014) with Richard Spencer in the Guardian online is indeed compelling. To teach students to learn about bacterial movement in a fun and memorable way, I encouraged them to 'dance like the bacteria' moving around the room waving their own appendages. Students have commented that this helped them recall the 
different movements and types of flagella, with one student wishing she could have danced in the exam to help her remember. A simple online search using 'Dance to learn science' brings up a lot of interesting studies.

\section{Bacterial Bohemian Rhapsody}

There is nothing like a good sing-song to reduce stress and help create connections with impromptu 'choir' members. At Charles Sturt University, about 58\% of students study by online - distance education. However, they need to attend Residential Schools to gain practical experience. In the first year microbiology subject - MCR101 (JH, TV), students come to a four-day residential school. Over the past 10 years we have surveyed the students when they arrive and about $80 \%$ are usually quite anxious about study as many are mature students who are upskilling and have not formally studied for some time. We help students to relax and learn by doing via some fun learning activities. A sing-song is just one artistic way to help them.

https://youtu.be/xgrumGCgwLQ

We Love Micro

People, all around us is a micro world on which we depend

It's true my friend, in your face, shouting these

words all over the place!

Chorus:

We Love

We Love

Micro! $x 2$

Some microbes they will kill you but overall they're good.

Without them we'd be dead! Yes that's what I said

Microbes rule the planet and on them we depend!

Chorus:x2

We acknowledge that we did not set out to evaluate which of our strategies improved learning, but there is ample evidence that providing a relaxing atmosphere does help.

\section{Humour}

There is evidence in the literature that the careful use of humour can assist learning and engagement of university students (Powell \& Andresen, 1985; Lovorn, 2008). In microbiology, the jokes tend to be small, but their effect can be huge (joke!). I use jokes on slides and even in online practice questions to help students de-stress and appreciate the fun of learning.

In an exam I strategically placed a 'microbiology' joke question (Q11) to help students relax. The comments back confirmed that it worked. One distance education student in a remote exam centre said that they burst out laughing and the three other students, in the room, doing different exams, looked at him strangely. He said "They probably thought I had gone hysterical and I couldn't tell them it was a joke I had just read!"

So here is the joke:

What do you call a fairy who doesn't wash?
A. Stinkerbell
B. The Strouth! fairy
C. Pongy in the park
D. Under the circumstances any answer is correct. 
I also encourage students to let me know any microbiology-related jokes that can be used to create a happy learning environment and/or will help memory. Here are some of them as examples:

\section{Did you hear about the jolly bacterium? It had an infectious laugh!}

Two bacteria walk into a bar. The barman said-No bacteria allowed here. The bacteria replied 'But we're Staff! (Staph.)

What do you give the person who has everything? "Antibiotics!"

Survey of first year University students over the years has shown that they really value humour as their comments not only say it helps them learn but also to relax in what would otherwise be a stressful time.

\section{Mobile phone photography}

In first year Botany practicals we developed a method, with students, to capture microscope images using mobile phones (Harper, Burrows, Moroni, \& Quinnell, 2015). Students used these images for assisting their learning but also shared them on social media for their artistic dimensions. It has been tricker to do this in microbiology class due to concerns over bacterial contamination of phones, but our technicians have come up with a mobile phone 'condom' that can be reused when swabbed with alcohol.

\section{The time travelling lab: Year 8 History}

The Microbiology subject convenor (TV) was approached by a High School teacher (TW) to see if some outreach activities could be provided for her class of year 8 students who were engaged in a history project about how hardship can result in innovations. These students were not very engaged with their school work so TW had sought to try a range of approaches which included art, to get them motivated to learn. TV asked me (JH) could I come up with a lab activity that would link to the black plague and ensuing innovations. After discussing ideas with an acting lecturer (DS) we came up with the idea of a time travelling lab where university acting students would be key characters in the history of microbiology. The principal actor was $\mathrm{ZH}$, who also later provided feedback on her experience in an interview with DS. There are some interesting recent publications that demonstrate the effectiveness of drama in teaching biological concepts (Stagg, 2019; Stagg \& Verde, 2019).

To set the scene in the lab, a short PowerPoint presentation was first shown (JH) to delineate the timeline the students would be travelling on. Their first stop was to visit a Plague Doctor from the Black Death during the Bubonic Plague of London (c1665). A student actor was dressed like a Plague Doctor (see below) who talked to the students about the role of their strange garb in keeping the plague at bay: The huge beak stuffed with perfumes and spices to keep out bad air (miasmas), large hat to protect from the sun, long wax covered coat and gloves to protect from sputum, red glasses (light). This paraphernalia highlighted the superstitions around how the plague was spread because at the time microbes had not been discovered.

To supplement our horror and immersion of the time, the high school students shared images of the buboes - infectious swellings drawn on their necks to simulate lymph nodes infected with the plague bacterium Yersinia pestis (Figure 2). The value of the ancient power in storytelling also came across as the students were mesmerised and totally accepted our construct coming with us on the journey like a great play audience. As students moved a little further along the timeline toward the present, they met a Dutch clothes merchant, Antonie van 
Leeuwenhoek (1632-1723), who was the first person to see bacteria and protozoa through a microscope and describe them. Dr Ignaz Semmelweis (1818-1865) talked about how from 1847 he tried to introduce handwashing in chlorine solution to reduce the incidence of the deadly puerperal (childbed) fever in birthing mothers. He noticed that the incidence of death was five times greater in facilities run by doctors rather than midwives. The difference? Midwives did not do autopsies while the doctors did and then did not wash their hands afterwards! Poor Dr Semmelweis found it difficult to convince doctors, and he lost his job more than once. He later lost his mind and died in an asylum through mistreatment. A very sad story yet he was right and is acknowledged now for his pioneering work. Handwashing is the single most important thing you can do to prevent infection!
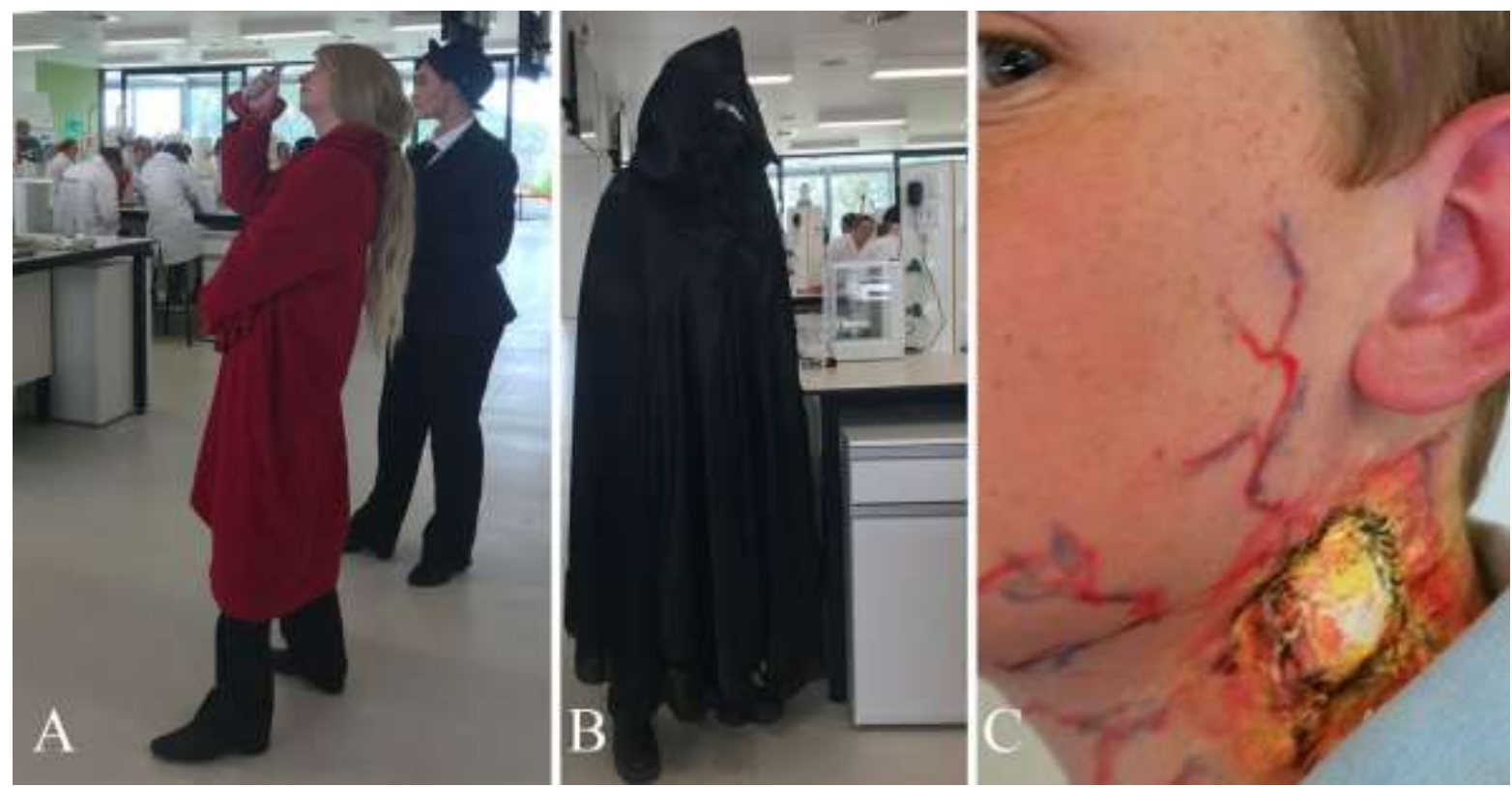

Figure 2: A. Antonie van Leewenhoek looks through his microscope while Dr Semmelweis wonders who hasn't washed their hands! B. A Plague Doctor stands vigil and C. a buboe develops

\section{Invisible worlds for small people: Year 2, primary}

For children, the world of microbiology encompasses a world of invisible wonder. This wonder was apparent at Harcourt Valley Primary School (Victoria, Australia) during a day of immersion teaching and learning for the Grade 2 students (6-7-year-olds). On cursory inspection, one may think that young children are limited in their comprehension and learning when material is complex and outside their realm of understanding. However, there is evidence that children can learn complex material when it is linked with objects and experience in their everyday lives and when it can be meshed with engaging stories and hands-on tactile learning inherent in art (Keleman, Emmons, Schillaci, \& Ganea, 2014).

At the start of the day, after introductions by the teachers to the facilitators (JH and CC), students were presented with a short animation made by local high school students on dividing yeast cells. This animation involved music and coloured captions to match the stages of division in budding yeasts, along with simple labels depicting cell organelles. The students then performed their own experiment with yeast, warm water, sugar and water. The gas $\mathrm{CO}_{2}$ given off by the reproducing and respiring yeast blew up coloured balloons. The children then drew their experiment as a pictorial representation (Figure 3A \& B). 
During a morning tea break the students were presented with blank badges to write their names on. To our surprise, they chose names based on the terminology they had encountered in the morning class; Dr Bacteria and Mr Microbe were some of those chosen. They then started a game outside based on their characters. By the end of the morning tea break, they were using many of the terms we had introduced in the morning session. After the break, the students came back into the classroom and began bun making with the ingredients from their first experiment, namely sugar, water and yeast as well as some dried fruit and flour. As the buns rose, they could see clearly the link between the dividing and reproducing yeast cells, and the carbon dioxide gas produced during respiration. The same gas that blew up their coloured balloons 'blew up the bread"

While students waited for the bread to bake, year 6 students assisted them in getting some material to look at under a digital Dino lite microscope attached to a computer (Figure 3C). Students took their own images, which were printed, and the school received a copy of them all, while each student got their own image (e.g. Figure 3). Scanning electron micrographs (taken by JH) of fly heads (Figure 3D), Agapanthus pollen (Figure 3E), bee stings, house dust, kangaroo poo and other interesting things seen in close up were also presented to the students as artefacts for discussion. The afternoon was finished with a feast of fruit buns, made by the children, along with a budding yeast cell cake decorated with icing cell organelles.

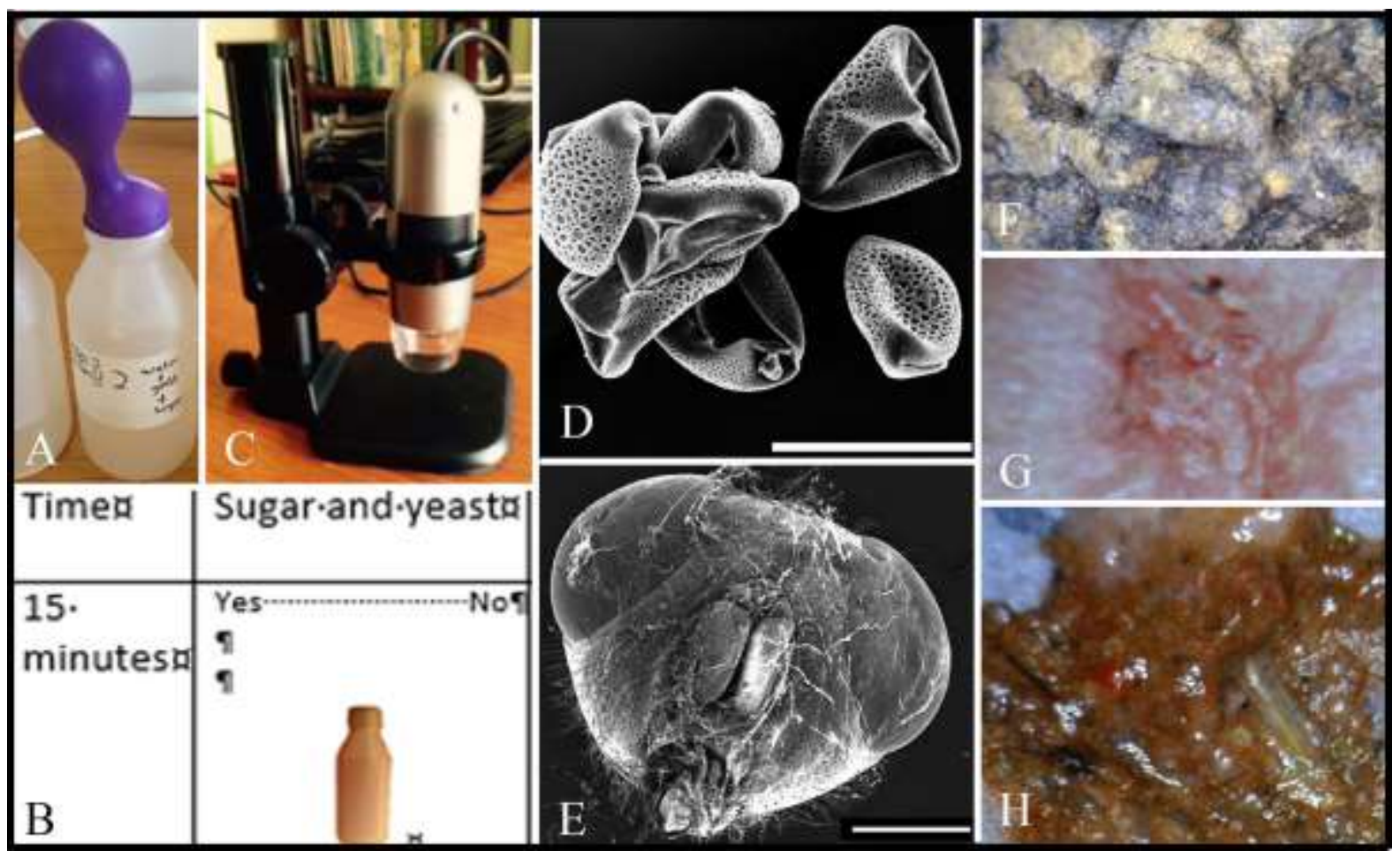

Figure 3: A. Students performed a classic yeast respiration experiment with carbondioxide inflating a balloon. B. Section of the results table with bottle for students to draw how much the balloon inflated under different experimental conditions $\mathrm{C}$. Dinolight microscope students used to take images. D. Agapanthus pollen. E. Fly head being devoured by a fungus; Images taken by students F. Quandong fruit, G. skin blemish H. red algae.

At the end of the afternoon, the children were presented with a short and simple survey of nine questions. The purpose was to gather information on their learnings and recollections of the day. There were seventeen responses, one for every student. One question was based directly 
on both the bun making, as well as the coloured balloon experience. It was "What is the name of the gas that produces 'lift off' (referring to yeast)?" For this response, the answers were very consistent. Seventeen out of seventeen children answered carbon dioxide. This experiment, in particular, was very visual. It involved the bottle with yeast, warm water and sugar causing a coloured balloon to inflate. The remaining containers under different experimental conditions together with the control remained flaccid. The children then filled out a graph by drawing the balloon shape and comparing the balloon shapes between treatments. Later on in the afternoon, they used the same ingredients together with flour and currants to make their buns. This supported the conceptual knowledge with practised based learning involving the visual elements (colour and shape of the balloon), art-based learning (drawing the end result of the experiment) and hands-on learning (adding the same ingredients to their buns, kneading them and watching them rise). This combination was successful in reinforcing the theoretical knowledge provided earlier in the day. The outcome of the survey was a strong positive response in terms of this question. The other answers were much more variable.

The immersion art science workshop can be a powerful teaching tool for young children (Halpine, 2004). On this day, the invisible world of wonder that is microbiology was made visible and bought to life through hands-on art meets sciences experiences. The multidisciplinary nature of the teaching elements including role play, the use of familiar everyday objects such as balloons, baking material and art equipment together with experimental techniques and scientific data collection. This can be a powerful tool to reinforce and consolidate student learning (Bopegedera, 2005; Cowrie \& Otrel-Cass, 2011). This study was limited by the small number of students, it being a pilot study, however, further investigation on the combination of teaching techniques and how they may reinforce conceptual learning would be of merit. It could then be ascertained whether each different method of presenting material advantaged different types of learners (visual, aural, tactile) or whether it was the repetition of the concept using different media that was the key to the success.

\section{I wonder...conversations with an artist}

In our search to blur art and science in order to see how we can improve our own and our student's creativity in learning, we have come across literature describing a transdisciplinary approach (Bernstein, 2015). This can be seen as bringing different disciplines together such as artists and scientists in a way that the divisions are blurred and it is argued to be the way to help solve the "wicked problems" of the world. We are only at the beginning of our exploration but in discussions between an artist (DS) and a scientist (JH), it was revealed that we could take a transdisciplinary approach to look at the science, geography, language, history, design, music, stories, spirituality, joy and heartache as multilayered paths that are danced and sung in a complex system of knowledge sharing and transference (Sweeney, 2017). Stories told through song, dance and design embody ways to make sense of specific places for the participant and the viewer. This is encompassed in the words "I wonder..." DS was introduced to the 'wonder exercise' while working in Centennial Park, Sydney, as an Education Ranger. Here he met Victoria Mew, who works with outdoor activities for children. One of the activities she shared was the basis for this approach to begin reaching beyond our current cultural awareness. This activity works equally well with children or adults.

\section{The 'wonder exercise'}

Participants are asked to work in pairs. Each is asked to take a leaf and, in turns, pose the following to each other, start with, "I wonder ..." to describe aspects that you observe of your 
chosen leaf'. After a couple of minutes, participants are asked for some examples of what they wondered together. When we start with "I wonder ..." questions become more important than answers. It is a starting point. "I wonder...."What if you actually felt you were the leaf, that tree or the sky? "I wonder...." about ways to understand country closer to an Aboriginal awareness, not caged in or out? Just stay open to possibilities. How can we engage with and approach these knowledges openly and respectfully? How do we engage artistically and scientifically contemporaneously?

"I wonder..." is an example of the integrative process where imagination and enquiry drive each other. The teacher becomes the catalyst for the creation of imaginative learning opportunities and along the way knowledge is generated in a 'questful' meaning-making profound and rich way. As we begin to share observations, each person is not only to wonder further about the subject they have considered but also be inspired by the creativity and imagination of their peers opening up new avenues of thought. To name for instance a plant with its scientifically determined Latin name may allow you to identify it anywhere in the world. However, this nomenclature can also mask the culturally rich parameters that a local name may provide in different communities. For instance, when the word "weed" is used what do you think of? Our thought (DS \& JH) is usually of something that you want rid of that is not welcome, that may cause harm to you or the environment. In actual fact, it is a very successful plant that is just out of place. A canola plant is a weed in a wheat field.

When an individual is enabled to shine their light of discovery in wonder, everyone benefits. The observations of a graphic artist are different to an orchestral musician, to a crime fiction writer to an entomologist to a lichenologist. Our gender, cultural backgrounds and all that has shaped us provide just what we need to wonder and this process is especially valuable if we are ready to wonder at someone else's wonder. The surprise in realising that people perceive differently opens discussion, opens possibilities. The "I wonder..." conversation springboards from idea to idea without terminating in a rigid concretized definition. If we stretch scientific inquiry including the arts so that STEM becomes STEAM the meeting point is not in the concrete but in the possibility of wonderment - of new ways of perceiving and explaining (L'Ecuyer, 2014).

\section{Concluding remarks}

Writing this article with my colleagues has enabled reflection on our approaches to learning and teaching and indeed life. The team has benefitted from the approach used in this subject leading to innovative teaching approaches in other subjects they teach. For me (JH) I have realised that I am not a scientist nor an artist but both and that to not bring these parts of me which are only separated in our view does not fully acknowledge who I am. As Shakespeare once wrote "To thine own self be true". In her reflection on STEM to STEAM (Quinnell, 2019), Rosanne has realised that: "These Science-Art moments have given me permission to be myself, to exhale." I ( JH) find that I breathe better too when I am there but that's another story...!

\section{Acknowledgements}

Thanks to everyone involved in this ongoing adventure: to the CSU technical staff: Natalie Alison, Rhonda Beecher, Jenni Horsnell, Lyn Matthews, Therese Moon, Kerry Shirmer, David Thompson, and Charmaine Carlisle for providing excellent assistance and supporting our outreach activities. To the staff at Harcourt Valley Primary School, Victoria for their willingness to allow us into their School for an immersive day. To Josef Murwood who became a Plague doctor at a moment's notice, Eleanor Gates-Stuart, our new Art-Science Professor, for her child-like enthusiasm and discussions, and our students who are a continuing inspiration as is our collaboration, merging disciplines - they disappear and what is left is people who love to have fun! 


\section{References}

Bernstein , J. H (2015) Transdisciplinarity: A review of its origins, development, and current issues.

Journal of Research Practice 11(1), 1-20. http://jrp.icaap.org/index.php/jrp/article/view/510/412

Bopegedera, A. M. R. P. (2005). The art and science of light. An interdisciplinary teaching and learning experience. Journal of Chemical Education, 82 (1), 55.

Cowie, B. \& Otrel-Cass, K. (2011) Exploring the value of 'horizontal' learning in early years science classrooms, Early Years, 31:3, 285-295, DOI: 10.1080/09575146.2011.609157

De Morgan, A. (1915). p191. In A Budget of Paradoxes (2 ${ }^{\text {nd }}$ Ed) M Smith (Ed.) The Open Court Publishing Company, Chicago

Haiko, J., Westerlund-Wikström, B. (2013) The Role of the bacterial flagellum in adhesion and virulence. Biology 2, 1242-1267; doi:10.3390/biology2041242

Halpine, S. M. (2004). Introducing molecular visualization to primary schools in California: The STArt! teaching science through art program. Journal of Chemical Education, 81(10), 1431.

Hardiman, M. M., John Bull, R.M., Carrana, D.T., Shelton, A. (2019) The effects of arts-integrated instruction 'on memory for science content, Trends in Neuroscience Education 14, $25-32$.

Harper, J. D. I., Burrows, G. E., Moroni, J. S. Quinnell, R. (2015) Mobile Botany: Smart phone photography in practical classes enhances student engagement. The American Biology Teacher 77, 699-702

Keleman, D., Emmons N. A., Schillaci, R.S., Ganea, P.A. (2014). Young children can be taught basic natural selection using a picture-storybook intervention. Psychological Science 1-10 DOI: $10.1177 / 0956797613516009$

LaMore, R., Root-Bernstein, R., Root-Bernstein, M., Schweitzer, J.H., Lawton, J.L., Roraback, E., Peruski, A., VanDyke, M., Fernandez, L. (2013) Arts and crafts: critical to economic innovation. Economic Development Quarterly 27, 221-229

Lang, R.J. Origami Retrieved 26 April, 2019 https://langorigami.com/about-robert-j-lang/

L'Ecuyer, C. (2014). The wonder approach to learning. Frontiers of Human Neuroscience 8, 1-8

Lovorn, M. G. (2008) Humor in the home and in the classroom: The benefits of laughing while we learn. Journal of Education and Human Development 2 (1) 1-12

Moens, S., Vanderleyden, J. (1996). Functions of bacterial flagella. Critical Review of Microbiology 22 (2), $67-$ 100.

Papert, S. (1980) Mindstorms, Children, computers and powerful ideas; Basic Books: New York, 1980; pp 3854.

Powell, J.P, Andresen, L.W. (1985) Humour and teaching in higher education. Studies in Higher Education, 10 (1), 79-90, DOI: 10.1080/03075078512331378726

OECD (2014), “Indicator D1: How much time do students spend in the classroom?”, In Education at a Glance OECD Indicators, OECD Publishing. Retrieved 2 April, 2019: http://dx.doi.org/10.1787/888933119530

Primary Science Teaching Survey 2014 Retrieved 2 April, 2019: https://asta.edu.au/programs/assist/primary_science teaching_survey

Quinnell, R (2019) Shifting from STEM to STEAM - reflecting on academic identity and scholarship. This issue.

Ranshaw, D. and Wise, E. (2014). Understanding the CSU First in Family student. Produced by: Western Research Institute for Charles Sturt University Retrieved 1 April, 2019

https://www.csu.edu.au/_data/assets/pdf file/0008/1292471/CSU-First-in-Family-Survey-Results.pdf

Root-Bernstein, M., Root-Bernstein, R., (2010) Retrieved 26 April, 2019 https://www.psychologytoday.com/au/blog/imagine/201003/einstein-creative-thinking-music-and-theintuitive-art-scientific-imagination

Root-Bernstein, R. S., Bernstein, M., \& Garnier, H. W. (1995). Correlations between avocations, scientific style, and professional impact of thirty-eight scientists of the Eiduson Study. Creativity Research Journal, 8, 115137.

Scheffer, M., Bascompte, J., Bjordam, T. K., Carpenter, S. R., Clarke, L. B., Folke, C., Marquet, P., Mazzeo, N., Meerhoff, M., Sala, O., Westley, F. R. 2015. Dual thinking for scientists. Ecology and Society 20 (2): 3.; http://dx.doi.org/10.5751/ES-07434-200203

Sweeney, D. (2017). I Wonder ... Indigenous corroborees and masked dances in Northwest Australia. pp 377384. Building Sustainability with the Arts: Proceedings of the 2 nd National Ecoarts Australis Conference, Cambridge Scholars Publishing

Stagg, B. C. (2019): Meeting Linnaeus: improving comprehension of biological classification and attitudes to plants using drama in primary science education, Research. Science \& Technological Education, 1-19 DOI: $10.1080 / 02635143.2019 .1605347$ 
Stagg, B. C. \& Verde, M. F. (2019) Story of a seed: educational theatre improves students' comprehension of plant reproduction and attitudes to plants in primary science education, Research in Science \& Technological Education, 37:1, 15-35, DOI: 10.1080/02635143.2018.1455655

Tingay, S. (2018). Indigenous Australian artists and astrophysicists come together to communicate science and culture via art. Journal of Science Communication, 17 (04), CN02. https://doi.org/10.22323/2.17040302.

Viney, L. (2016).Good vibrations: the role of music in Einstein's thinking. Retrieved 26 January, 2019: https://theconversation.com/good-vibrations-the-role-of-music-in-einsteins-thinking-54725

Welham, H. (2014) Guardian interview article. Strictly biology: how I use dance routines to inspire biology students. Richard Spencer Retrieved 22 April, 2019: https://www.theguardian.com/teachernetwork/2014/dec/28/biology-lessons-science-teacher 